\title{
Effect of Roy Adaptation Model on Sexual Function and Spousal Support among Women after Total Hysterectomy.
}

\author{
Entesar Fatouh Abed Elmoneim ${ }^{1}$, Gehan E.Ghonemy ${ }^{2}$, Nagia Ibrahim Hassan ${ }^{3}$ \\ ${ }^{1}$ Maternal \& Newborn Health Nursing, Faculty of Nursing, Helwan University. \\ ${ }^{2}$ Maternal \& Newborn Health Nursing, Faculty of Nursing, Cairo University. \\ ${ }^{3}$ Psychiatric Nursing and Mental Health, Damanhour University, Egypt.
}

\begin{abstract}
:
Background: Hysterectomy remains one of the most common major gynecological surgery. Postoperative sexual function is a concern for many women and their partners. In this respect, a beneficial effect of hysterectomy for benign disease independent of surgical techniques or removal of the cervix has been demonstrated in the past decade by the majority of studies

Aim: The purpose of this study was to determine the effect of Roy Adaptation Model on sexual function and spousal support among women with total hysterectomy.

Method: The study was planned and carried out as quasi-experimental prospective study design. The purposive sample formed of 60 women who had been operated of the total hysterectomy and met the inclusion criteria were recruited.The participated women were randomized as a study group $(n=30)$ and control group $(n=30)$. Women in control group benefited only from the clinical care. Women in Study group encouraged to receive an educational program were interviewed post-operative before discharge to collect the basic data and 4 weeks after hysterectomy to implement the educational program, and after $6^{\text {th }}$ month of hysterectomy to evaluate the effect of program.

Tools: Data were collected with the questionnaire form, Female Sexual Function Index (FSFI) and EducationalSupportive Program. The FSFI was applied two times to the women (first time 4 weeks before hysterectomy and the second times after six months of hysterectomy).

Results: In each group, a significant improvement in women's knowledge attitude and sexual function was demonstrated after the intervention $(P<0.001)$. The mean total of sexual function score increased to a greater extent in the experimental group (difference $16.95 \pm 6.33$ ) than in the control group (difference $4.35 \pm 1.94 ; P<$ 0.001).

Conclusion: The findings confirm the effectiveness of an educational program based on Roy Adaptation Model have positive effect on sexual function and spousal support among women with total hysterectomy.
\end{abstract}

Key words: Educational program, sexual function, hysterectomy, Roy adaptation model, spousal support

\section{Introduction}

Hysterectomy is one of the most common gynecological surgical procedures in the United States of America (USA). More than 600.000 in the United States and around 140.000 in Germany hysterectomies are performed each year. [1]. The highest rates are found in the South and Midwest, and more common among African-American women. In Egypt, annual incidence rate for hysterectomy was 165 per 100,000 hysterectomies are performed each year according to the National Center for Health Statistics. Nearly $90 \%$ of hysterectomies are done for benign symptomatic disorders [2].Hysterectomy has traditionally been regarded as the definitive surgical treatment for heavy menstrual bleeding, which consider the most frequent reasons for performing hysterectomy, other common indications include fibroids, chronic pelvic pain, genital prolapsed, and malignancy of the uterus. [3].

Total abdominal hysterectomy involves the removal of both the body of the uterus and the cervix, whereas subtotal abdominal hysterectomy conserves the cervix. Because the subtotal procedure minimizes anatomical disruption, it may be less likely to have adverse effects than total hysterectomy .Hysterectomy can be followed by various short- and long-term complications. The most important long-term effects are sexual problems, chronic pain, bladder dysfunction and bowel dysfunction [4]. Hysterectomy is a major surgical procedure with potential for significant physical and emotional complications.[3]. However, the psychological, physical and sexual consequences of hysterectomy are arising because hysterectomy affects the nerve supply of the uterus and the anatomy of the pelvis. Most of women are anxious about the negative effects of hysterectomy

DOI: 10.9790/1959-060205130140 $\quad$ www.iosrjournals.org $130 \mid$ Page


on sexual function [5] and can believe that their womanhood is impaired. The effect of hysterectomy on the general quality of life and on sexual functions varies. Loss of sexual desire, decrease in the sexual activity frequency, in sexual response, and in sexual saturation, difficulty in orgasm, decrease in genital sensation, painful sexual intercourse, shortening of the length of the vagina, loss of penetration of the penis, and decrease in vaginal elasticity and in vaginal lubrication are among the complaints experienced after hysterectomy [6].

The psychological and sexual complications of hysterectomy can affect sexual relations in couples , so should be paying attention to the women's knowledge, thoughts, and attitudes toward sex is essential for restoring successful sexual function. In fact, a dedicated educational program can improve sexual function in this group of women [7]. Consequently, sexual counseling and education must be considered for women with hysterectomy, with matters addressed including sexual beliefs, attitudes, and perceptions [8].For an educational program to be successful, it is necessary to use a suitable health education model [9].

During the past decade, there continues to be a lack of research with a focus on husband experience in the context of hysterectomies. This despite the findings of two qualitative studies, one from China, and the other from Brazil, that men had considerable concerns about changes in postoperative sexuality or sexual abstinence around the time of hysterectomy of their partner [10,11]. Unchanged or improved sexual satisfaction for men, with no significant difference after total abdominal hysterectomy or subtotal abdominal hysterectomy, has been reported in a retrospective study from Norway [12].After subtotal hysterectomy, more men noticed during intercourse that the uterus had been removed, but none of these partners experienced this as negative. In summary, for the spousal, sexual function after benign hysterectomy appears to be an important issue and some evidence exists that men can also expect unchanged or improved sexual satisfaction, regardless of removal of thecervix.Providing quality care and educations to post hysterectomy women can promote their adaptation to that changes. Women's attendance at healthcare settings provides healthcare professionals with excellent opportunities for delivering biopsychosocial care and educations to them. However, in our country, healthcare professionals pay little attention to psychological \& social care delivery to pregnant women [13]. The current post-hysterectomy care programs which are offered in Egyptian health care settings mainly focus on women's physiological problems and needs while taking psychological aspects of gynecological care for granted. One of the practical care delivery models which mainly focus on promoting individuals' adaptation in unique, highpressure situations such as hysterectomy is the Roy's adaptation model (RAM)[14]. This model can be employed by healthcare professionals for promoting women's adaptation to post hysterectomy sexual-related problems [15].

According to the RAM, adaptation is a set of processes through which an individual responds to environmental changes or stimuli. The aim of nursing interventions in the RAM is to enhance adaptive responses in each of the four physiological, self-concept, interdependence, and role function modes [16].As one of the adaptive modes in the RAM, self-concept is defined as individuals' feelings about oneself and is influenced by many factors chiefly others' reactions. Self-concept consists of three components including physical self, personal self, and interpersonal self. Physical self is an individual's perception of his/ her own body while interpersonal self is an individual's perception in relation with others [17]. The RAM, particularly assesses and focuses on the self-concept mode and pays a special attention to it. Other key concepts of the RAM are focal stimulus, contextual stimuli, and residual stimuli. Focal stimulus is a stimulus, which directly affects individual and has the greatest role in his/her ineffective adaptation [18].Contextual stimuli are not as immediate as the focal stimulus, but may negatively affect it. Residual stimuli relate to individual's personal traits, experiences, and beliefs and their effects on the immediate situation are not obvious. Previous studies have shown the effectiveness of the RAM in promoting clients' adaptation [19] .However, to the best of our knowledge, only a few studies have investigated the effects of the RAM on women's adaptation to post-hysterectomy -related sexual problems

\section{Significance of the Study:}

Sexual function plays a main role in marital relationship [20]. In fact, sexual satisfaction is a natural need, which is similar with other basic needs.Therefore, the association between hysterectomy and sexual functioning remains unclear because of the apparent incongruous evidence showing both beneficial and detrimental effects. Caring for women who undergo hysterectomies are ignored in most hospitals although complications following hysterectomy may expose women to morbidity and mortality. One of the main roles of nurses is to assess problems in this area to be able to provide anticipatory guidance related to treatment and the resumption of sexual activity, but this is one aspect of care that has been largely ignored by health care providers. .However, sexual health care still inadequate addressed due to barriers such as incorrect assumptions and beliefs toward sexual issues. [21, 22] A limited number of studies relevant to sexual life among women after radical hysterectomy are found in Egypt. Also the lack of comprehensive and systematic studies evaluating the impact of education on sexual function (especially studies based on a systematic needs assessment), and the lack of 
attention to sexual problems among women, the present study was conducted to determine the impact of educational intervention on sexual function among women with hysterectomy.

\section{Aim of the study:}

The aim was to address the effect of Roy Adaptation Model on sexual function and spousal support among women with total hysterectomy.

\section{Study hypothesis:}

1. It was hypothesized that women with total hysterectomy undergo educational intervention based on Roy Adaptation Model will have a positive effect on their sexual function rather than who did not had interventions.

2. It was hypothesized that women with total hysterectomy undergo educational intervention based on Roy Adaptation Model will have a higher spousal support rather than who did not had interventions.

\section{Subjects and Methods:}

A-Research design: A quasi-experimental research design was utilized in this study.

B-Study setting: The study was conducted in the gynecological inpatient's ward and outpatient's clinics of El Manial University hospital - Cairo -Egypt.

\section{C-Sample:}

A purposive sample of 60 women who had totalhysterectomy, who were selected randomly divided into two equal study/control groups. The women in the control group benefited only from the clinical care, they were not given any additional education $(n=30)$. The women in the study group $(n=30)$ were given the clinical care plus individual education program based on the Roy Adaptation Model, after the operation, before being discharged. The study was conducted from January 2016 to September, 2016.

C.1: Inclusioncriteria: Read and write, married with active sexual life, free from chronic disease/ psychiatric problems, don't use drugs may affect the sexual health, no history of drug abuse \&no history of malignancies

\section{C.2: Sample size:}

A total of 60 of women are recruited from the previous mentioned setting. They were randomly allocated to the two groups. Those who were admitted the ward during the first two days of week were selected as the intervention group and the others of $2^{\text {nd }}$ two days were assigned to the control group.

D-Tools of data collection:

D.1: Interviewing Questionnaire: Data will be collect by including five parts developed by researcher:

D.1.1:Socio-demographic characteristics to assess: -Women's age, level of education, occupation, duration of married, residence.

D.1.2: Menstrual history to assess: age of menarche, duration, interval

D.1.3: Obstetric and gynecological history to assess: numbers of gravidity, numbers of parity

D.1.4: Knowledge and attitude of hysterectomy operation such as: complains before surgery, treatment of complains.

\section{D.II : Female Sexual Function Index (FSFI).}

This tool was formulated by Rosen and Meston (2002) [23] to analyze female sexual function during the past month prior to the interview day. It was translated into Arabic to suit Egyptian culture, the Arabic (FSFI) tool was tested for validity, reliability, and was locally accepted to be used in the assessment of Egyptian female sexuality by Anis (2011) [24]. It comprises 19 multiple choice questions that measure 6, domains, including desire domain (2 questions), arousal (4 questions), lubrication (4questions), orgasm (3 questions), satisfaction (3 questions) and sexual pain (3 questions). Each domain scored from 0/1 (no sexual activity or sexual dysfunction, respectively) to 5 (suggestive of normal sexual activity). The domain score determined by adding the score of the questions that comprise the domain and multiply the sum by the domain factor (i.e., desire 0.6, arousal and lubrication 0.3 , orgasm, satisfaction and pain 0.4 ). Likert scale was used to record the overall score of sexual function, minimum score was $\mathbf{( 2 . 0 )}$ and maximum score was (36.0). If the total female score was below or equal (28.1), she was considered to have female sexual dysfunction according to Arabic translated (FSFI). While the full-scale score calculated by adding the six domain scores $(=2$ to 36$)$. A total score of 28.1 was taken as the cutoff point for the Arabic version FSFI to distinguish between women with FSD and those with normal function (sensitivity $96.7 \%$, specificity $93.2 \%$ ).

\section{III : Spousal Support Scale}

The consists of a 13-item, five-point Likert-type scale (one strongly disagree to five strongly agree) designed to measure spousal support behavior for women with hysterectomies. The scores range from 13 to 65 
and high total scores indicate a higher level of support from spouse. In the study by Chang (1989) ${ }^{[25]}$ the internal consistency coefficient of alpha was 0.85 . In this study, the Cronbach's alpha value was 0.77 .For this study, items were summed into a composite variable to categories as low support scores $(<21.5)$,Moderate support (21.5- <43) ) High support ( 43- 65 ).

\section{Tool Validity and Reliability}

The designed interviewing questionnaire schedule was submitted to a panel of five expert professors in obstetric and gynecological medical and nursing experts field to test the content validity, modifications were carried out according to the panel judgment on clarity of sentences and appropriateness of content. Face validity was tested through an extensive review of literatures about hormonal contraception and its effect on female sexual function .

\section{E. Ethical consideration:}

An official permission was obtained using proper channel of communication. The directors of El Manial University hospital was asked for permission through a formal letter. A full explanation of the aim of the study was given to the women stressing on the confidentiality of the information and the importance of the study oral /written consent will be taken from the women: It's a written consent was obtain from those who accepted the condition of the study. The women were understand that they have the option to withdrawal from the study at any time. Patients in the control group also received the educational and counseling services in the form of an educational package for an ethical consideration.

\section{F- Pilot study}

After review of the questionnaire by experts and its approval, a pilot study was carried out before starting the actual data collection on $10 \%$ of cases, to ensure stability of the answers and these were not included in the total sample of the research work. The purpose of the pilot study was to ascertain the clarity, and applicability of the study tools, and to identify the obstacles and problems that may be encountered during data collection. It also helped to estimate the time needed to fill in the questionnaire. Based on the results of the pilot study, modifications, clarifications, omissions, and rearrangement of some questions were done.

\section{G. Fieldwork:}

- Data collection was carried out during the period from January to December 2016. The study consumed 12 months, preparation about three months, followed by six months for implementation and three months for data analysis and evaluation. Prior to data collection, the researcher interviewed with the eligible women, introduced herself to each one, a full explanation about the aim, the scope of the study was given to obtain women acceptance, and they were assured of confidentiality of the data. They were also informed that they could withdraw from the study at any time without giving any justification. Thereafter, informed written consent was obtained from the women. Eligible womenwereallocated randomly to one of two groups (30 women each) .The women completed the questionnaire in a private room to minimize distraction and enhance privacy and dignity.

- Data were collected via a self-administered questionnaire form, the interview questionnaire was done individually in a separate room, one-to-one and with face to face interview method to assess the women's sociodemographic data, full obstetric data, husband support condition and sexual function information and performance prior to the implementation of the study via Female Sexual Function Index (FSFI) . It has 19 items, which assess the six domains of sexual function including desire, arousal, lubrication, orgasm, satisfaction and pain. Women sexuality was evaluated with FSFI in 2 stages. First evaluations was made retrospective 4 weeks pre-surgery. (by asking about their sexuality before the complaints/symptoms had arisen was assessed at the first evaluation.). Second evaluation was made on the sixth post-operative month by appointments. Initially, patients' maladaptive behaviors and corresponding focal, contextual, and residual stimuli were identified and prioritized by using the study questionnaire as well as through conducting personal face-to-face interviews with the women. The study women maladaptive behaviors in the area of physical and interpersonal self-concept included disturbed body image, fear, low self-confidence, grief, sexual dysfunction, disturbed marital relationships, and impaired social interactions. The stimuli contributing to these maladaptive behaviors were a lack of knowledge related to post hysterectomy changes in physiological and, sexual \& psychological changes, spousal's lack of knowledge about the consequence of post-hysterectomy and the associating physiological changes, restrictions, and fear over one's own.

- An intervention program was developed based on the Roy Adaptation Model for eliminating or modifying the focal stimulus as well as for minimizing the effects of contextual and residual stimuli through enhancing women' adaptation capacity.It was provided only for the study group and according to the results obtained from the previous tool, as well as reviewing current literature; the researchers developed the needed information. It was prepared in the form of illustrated pamphlets with very simple Arabic explanations, which provided to the 
women and their spouses, which all husbands were invited to attend learning sessions. Use of virtual and electronic education during sessions to provides more clarification and the opportunity to receive social support for the development of consistent behaviors by supporting interaction between the research team and women. The program consisted of educational and counseling services provided by the researchers to the women and their spousal in the study group ,the women who met the inclusion criteria were encouraged to receive an educational program consisting of 2 sessions of 30-45 minutes each, with one session conducted in inpatient ward after hysterectomy /before discharge and the second session after four weeks of hysterectomy in the outpatient clinic during their follow-up management, The question-and-answer method was used to understanding of the topics, and encouragement for women to express their feelings about the hysterectomy. The contents of counseling sessions included hysterectomy, post hysterectomy sexual problems \& its cyclic changes and how to manage them (in relation to female sexual index), sexual attitudes and strategies and skills to improve sexual function, such as relaxation activities including walking, strengthening exercises for pelvic muscles, use of lubricating gels, and, effective communication before having sexual intercourse ,the role of stress and its effects on women's health, and fitness, so the women learned skills for stress and anger management and express their feelings about their new sexual adaptation .

- The control group received only routine hospital interventions regarding post hysterectomy care but not sexual education was given. Post-test was done after 6 months of hysterectomy to evaluate the effectiveness of educational program.

- The course of the study intervention lasted for six consecutive months. The follow-up care consisted of face-to-face and telephone contacts for answering women' questions and promoting their adherence to the delivered educations and counseling. Finally, all the study women were invited to complete the post-test. After conducting the posttest, patients in the control group also received the educational and counseling services in the form of an educational package for an ethical consideration.

\section{H. The limitations of the study:}

The limitations of the study are the relatively low case number, and sampling drop out due to long follow up duration. In addition, spousal support is not to that expected level, \& certain cases dropped because of lake of spousal supports.

\section{Statistical design:}

Data was tabulated and analyzed, all statistical calculations were done using computer session SPSS (Statistical Package for the Social Science; SPSS version 21). Descriptive statistics: data were presented in the form of mean \pm standard deviation or frequencies and percentages. Inferential statistics: Paired $(t)$ test was used to determine the difference between pretest and post-test evaluations of the same group . Chi-square test $\left(\chi^{2}\right)$ : was used to study association between two qualitative variables. Correlation between different variables were done using Pearson moment correlation. $\mathrm{P}$ values less than 0.05 will considered statistically significant.

\section{Results:}

Results of the current study discussed on the frame of the Roy adaptation model, in order to achieve the aim of the study, which is "Address the effect of Roy Adaptation Model on sexual function and spousal support among women with hysterectomy. The result describe the sociodemographic data, obstetrics \& gynecological data, female sexual function within the group \& between the controls\& study one. \& spousal support effect on the women's with hysterectomy. 
Table 1: Distribution of Socio-Demographic Characteristics and Hysterectomy Profile among Studied Sample N=60

\begin{tabular}{|c|c|c|c|c|c|c|}
\hline \multirow[t]{2}{*}{ Characteristics } & \multicolumn{2}{|c|}{ Study group $N=30$} & \multicolumn{2}{|c|}{ Control group $N=30$} & \multirow[t]{2}{*}{$\mathbf{X}^{2}$} & \multirow[t]{2}{*}{ P.value } \\
\hline & NO & $\%$ & NO & $\%$ & & \\
\hline \multicolumn{5}{|l|}{ Age in years } & \multirow[t]{6}{*}{0.467} & \multirow[t]{6}{*}{$>0.05$} \\
\hline$<30$ & 3 & 10.0 & 2 & 6.6 & & \\
\hline $30-<40$ & 8 & 26.7 & 9 & 30.0 & & \\
\hline $40-<50$ & 9 & 30.0 & 8 & 26.7 & & \\
\hline$>50$ & 10 & 33.3 & 11 & 36.7 & & \\
\hline Mean \pm SD & \multicolumn{2}{|c|}{$43.7 \pm 10.1$} & \multicolumn{2}{|c|}{$44.3 \pm 9.8$} & & \\
\hline \multicolumn{5}{|l|}{ Employment } & \multirow[t]{3}{*}{0.652} & \multirow[t]{3}{*}{$>0.05$} \\
\hline Employed & 11 & 36.7 & 12 & 40.0 & & \\
\hline Not Employed & 19 & 63.3 & 18 & 60.0 & & \\
\hline \multicolumn{5}{|l|}{ Education level } & \multirow{5}{*}{0.432} & \multirow{5}{*}{$>0.05$} \\
\hline Read and write & 10 & 33.3 & 11 & 36.7 & & \\
\hline Primary & 7 & 23.3 & 6 & 20.0 & & \\
\hline Secondary & 10 & 33.3 & 9 & 30.0 & & \\
\hline High education or more & 3 & 10.0 & 4 & 13.3 & & \\
\hline \multicolumn{5}{|l|}{ Marriage duration in years } & \multirow{4}{*}{0.429} & \multirow{4}{*}{$>0.05$} \\
\hline $1-10$ & 5 & 16.7 & 6 & 20.0 & & \\
\hline $11-20$ & 7 & 23.3 & 8 & 26.7 & & \\
\hline$\geq 20$ & 18 & 60.0 & 16 & 53.3 & & \\
\hline \multicolumn{5}{|l|}{ Reason for hysterectomy } & \multirow[t]{5}{*}{0.391} & \multirow[t]{5}{*}{$>0.05$} \\
\hline Fibroid & 9 & 30.0 & 10 & 33.3 & & \\
\hline Uterine prolapsed & 4 & 13.3 & 5 & 16.7 & & \\
\hline Continuous bleeding & 14 & 46.7 & 13 & 43.3 & & \\
\hline Others & 3 & 10.0 & 2 & 6.6 & & \\
\hline \multicolumn{5}{|l|}{ Hysterectomy type } & \multirow[t]{4}{*}{0.598} & \multirow[t]{4}{*}{$>0.05$} \\
\hline Abdominal & 28 & 93.4 & 27 & 90.0 & & \\
\hline Vaginal & 2 & 6.6 & 3 & 10.0 & & \\
\hline Laparoscopic & 0 & 0 & 0 & 0 & & \\
\hline
\end{tabular}

Table (1). Sociodemographic data reported that, the age ranged from 30-50 years old with average mean of $43.7 \pm 10.1$ for the study group $\& 44.3 \pm 9.8$ for the control one, without any significant differences between both group ( $\mathrm{t}=0.467 \& \mathrm{p} .>0.05$ ) . $63.3 \%$ of the study group not employed compared to $60 \%$ of the control one. Their level of education reported that about one third of both groups can read \& write, \& another one third had secondary level of education. In relation to the duration of marriage, more than half of both groups had married for $\geq 20$ (60\% \& 53.3\% for study \& control group respectively). In relation to the sample obstetrical profile, the study reported that $50 \%$ of the study group had gravida 3 to six compared to $53 \%$ of the control group. \& around $30 \%$ for both groups was either gravida 1 or 2 . While their parity was more than 3 among study \& control group $(46.7 \% \& 43.3 \%$ respectively). Only $40 \%$ of the study group had exposed to abortion compared to $50 \%$ of the control one (number of abortion either one time to two among both group). The results reported a source of homogeneity between both groups regarding their sociodemographic \& obstetrics profile. Regarding the reasons for hysterectomy as continuous bleeding was the major cause ( $46.7 \%$ among the study group \& 43.3 for the control one). In addition, their type of hysterectomy was abdominal among $93.4 \%$ of the study group while, its $90.0 \%$ for the control one. Only $6.6 \%$ of the study group had vaginal hysterectomy compared to $10.0 \%$ of the control group. 
Table (2). Distribution of the Sample According to their Knowledge, Attitude, and Sexual Function Scores

\begin{tabular}{|l|l|l|l|}
\hline Variable & Study group & Control group & P value \\
\hline & Mean score $\mathbf{\text { SD }}$ & Mean score $\mathbf{\text { SD }}$ & \\
\hline Knowledge & $23.8 \pm 3.2$ & $25.3 \pm 4.1$ & 0.234 \\
\hline Attitude & $31.4 \pm 8 . .9$ & $33.6 \pm 7.5$ & 0.523 \\
\hline Desire & $3.9 \pm 0.8$ & $4.2 \pm 0.8$ & 0.647 \\
\hline Arousal & $2.6 \pm 1.1$ & $2.8 \pm 1.5$ & 0.324 \\
\hline Lubrication & $2.3 \pm 1.0$ & $3.1 \pm 1.2$ & 0.115 \\
\hline Orgasm & $2.1 \pm 1.3$ & $3.0 \pm 1.3$ & 0.273 \\
\hline Satisfaction & $2.1 \pm 1.3$ & $2.9 \pm 1.4$ & 0.936 \\
\hline Pain & $4.2 \pm 0.8$ & $3.8 \pm 0.9$ & 0.171 \\
\hline Total score & $18.4 \pm 6.5$ & $19.7 \pm 6.3$ & 0.314 \\
\hline
\end{tabular}

* Significant At P $<0.5$

* * Significant At $\mathbf{P}<0.001$

- In Significant At P>0.5

Table (2). This table illustrates that the study results did not report any significant differences between the study \& control group in relation to their base line assessment of knowledge, attitude, sexual function elements \& pain level. Which reflecting homogeneity between both groups \& confirmed the inclusion criteria that they were selecting base on it.

Table (3). Distribution of the Sample According to their Sexual Function before and After 6 Month (Within-Group Comparison)

\begin{tabular}{|l|l|l|l|l|l|l|}
\hline \multirow{2}{*}{ Variable } & \multicolumn{3}{|c}{ Study group } & \multicolumn{3}{c|}{ Control group } \\
\cline { 2 - 7 } & Before & After 6 $^{\text {th }}$ month & P-Value & Before & After6 $^{\text {th }}$ month & P-Value \\
\hline Desire & $3.9 \pm 0.8$ & $12.7 \pm 0.2$ & $<0.001$ & $4.2 \pm 0.8$ & $8.5 \pm 0.5$ & $<0.001$ \\
\hline Arousal & $2.6 \pm 1.1$ & $4.9 \pm 0.5$ & $<0.001$ & $2.8 \pm 1.5$ & $3.3 \pm 1.4$ & 0.593 \\
\hline Lubrication & $2.3 \pm 1.0$ & $4.7 \pm 0.6$ & $<0.001$ & $3.1 \pm 1.2$ & $2.9 \pm 1.2$ & 0.433 \\
\hline Orgasm & $2.1 \pm 1.3$ & $4.5 \pm 0.7$ & $<0.001$ & $3.0 \pm 1.3$ & $2.7 \pm 1.4$ & 0.320 \\
\hline Satisfaction & $2.1 \pm 1.3$ & $4.8 \pm 0.5$ & $<0.001$ & $2.9 \pm 1.4$ & $3.2 \pm 1.5$ & 0.226 \\
\hline Pain & $4.2 \pm 0.8$ & $4.6 \pm 0.9$ & $<0.01$ & $3.8 \pm 0.9$ & $3.7 \pm 0.8$ & 0.304 \\
\hline Total score & $16.4 \pm 6.3$ & $35.2 \pm 3.4$ & $<0.001$ & $19.7 \pm 7.1$ & $25.9 \pm 6.8$ & $<0.001$ \\
\hline
\end{tabular}

* Significant At P<0.5 * *Significant At P<0.001 - In Significant At P>0.5

Table (3). Considering the sexual function within each group, the results reported significant differences within Study group before\& after six months of program. But reported no significant differences within control group except in items related to desire. While a total score reported a significant difference between both group after $6^{\text {Th }}$ months of hysterectomy (p. <0.001).

Table (4). Between-Group Comparison of Changes in Sexual Function after $6^{\text {th }}$ months.

\begin{tabular}{|l|l|l|l|}
\hline Variable & \multicolumn{1}{|c|}{$\begin{array}{c}\text { Study group } \\
\mathrm{N}=30\end{array}$} & $\begin{array}{c}\text { Control group } \\
\mathrm{N}=30\end{array}$ & $\boldsymbol{P}$ value \\
\hline Desire & $8.8 \pm 1.72$ & $4.3 \pm 2.19$ & $<0.001$ \\
\hline Arousal & $2.3 \pm 0.99$ & $0.5 \pm 0.13$ & $<0.001$ \\
\hline Lubrication & $2.4 \pm 1.23$ & $-0.2 \pm 0.22$ & $<0.001$ \\
\hline Orgasm & $2.4 \pm 1.17$ & $-0.3 \pm 1.63$ & $<0.001$ \\
\hline Satisfaction & $2.7 \pm 1.15$ & $0.3 \pm 0.39$ & $<0.001$ \\
\hline Pain & $0.4 \pm 1.42$ & $-0.1 \pm 0.4$ & $<0.01$ \\
\hline Total score & $\mathbf{1 9 . 0} \pm \mathbf{6 . 3 3}$ & $\mathbf{4 . 5} \pm \mathbf{1 . 9 4}$ & $<\mathbf{0 . 0 0 1}$ \\
\hline
\end{tabular}

* Significant at $\mathrm{P}<0.5 \quad * *$ Significant at $\mathrm{P}<0.001 \quad$ - In Significant at $\mathrm{P}>0.5$ 
Table (4) Results also revealed a significant change between the study \& control group in relation to FSFI variables. As the study group revealed higher scores rather than the control one, $(p<0.01$ or less). This result parallel to what the previous table reported.

Table (5) Distribution of the studied Sample According to their Spousal Support after hysterectomy in before and after intervention.

\begin{tabular}{|c|c|c|c|c|c|c|c|c|c|c|}
\hline \multirow{3}{*}{ Spousal support } & \multicolumn{5}{|c|}{ Study Group } & \multicolumn{5}{|c|}{ Control Group } \\
\hline & \multicolumn{2}{|c|}{ Before } & \multicolumn{2}{|c|}{ After $6^{\text {th }}$ months } & \multirow[t]{2}{*}{ P-Value } & \multicolumn{2}{|c|}{ Before } & \multicolumn{2}{|c|}{ After $6^{\text {th }}$ month } & \multirow[t]{2}{*}{ P-Value } \\
\hline & No & $\%$ & No & $\%$ & & No & $\%$ & No & $\%$ & \\
\hline low $(<21.5)$ & 23 & 76.7 & 7 & 23.3 & \multirow{4}{*}{$\begin{array}{l}\mathrm{T} 1=4.5 \\
<0.01\end{array}$} & 22 & 73.3 & 19 & 63.3 & \multirow{4}{*}{$\begin{array}{l}\mathrm{T} 2=0.56 \\
0.05\end{array}$} \\
\hline Moderate $(21.5-<43))$ & 5 & 16.6 & 13 & 43.3 & & 6 & 19.9 & 8 & 26.7 & \\
\hline High (43-65) & 2 & 6.6 & 10 & 33.3 & & 1 & 3.3 & 3 & 10.0 & \\
\hline Total mean score & \multicolumn{2}{|c|}{$17.4 \pm 12.7$} & \multicolumn{2}{|c|}{$34.4 \pm 16.3$} & & \multicolumn{2}{|c|}{$18.9 \pm 13.1$} & \multicolumn{2}{|c|}{$20.9 \pm 14.5$} & \\
\hline T- test & & & & $T 3=0$ & $\mathbf{P}>$ & & $T 4=3$ & $P<0$ & & \\
\hline
\end{tabular}

$\mathrm{T} 1$ :Between before \& after intervention in study G.

T2: Between Before \&after in control G.

T3 :between study\& control G. before intervention.

$\mathrm{T} 4$ :Between study\& control G .after intervention

Table (5)\&figure (1) :The spousal support for their women with hysterectomy, show marked group different (within the study group) pre-education than post education (Roys adaptation ,self-concept ) as ( $\mathrm{T} 1=6.9 * \mathrm{P}<0.01$ ), as well as marked significant differences between the study \& control group as ( $\left.\mathrm{T} 4=2.4 \quad \mathrm{P}<0.05^{*}\right)$.
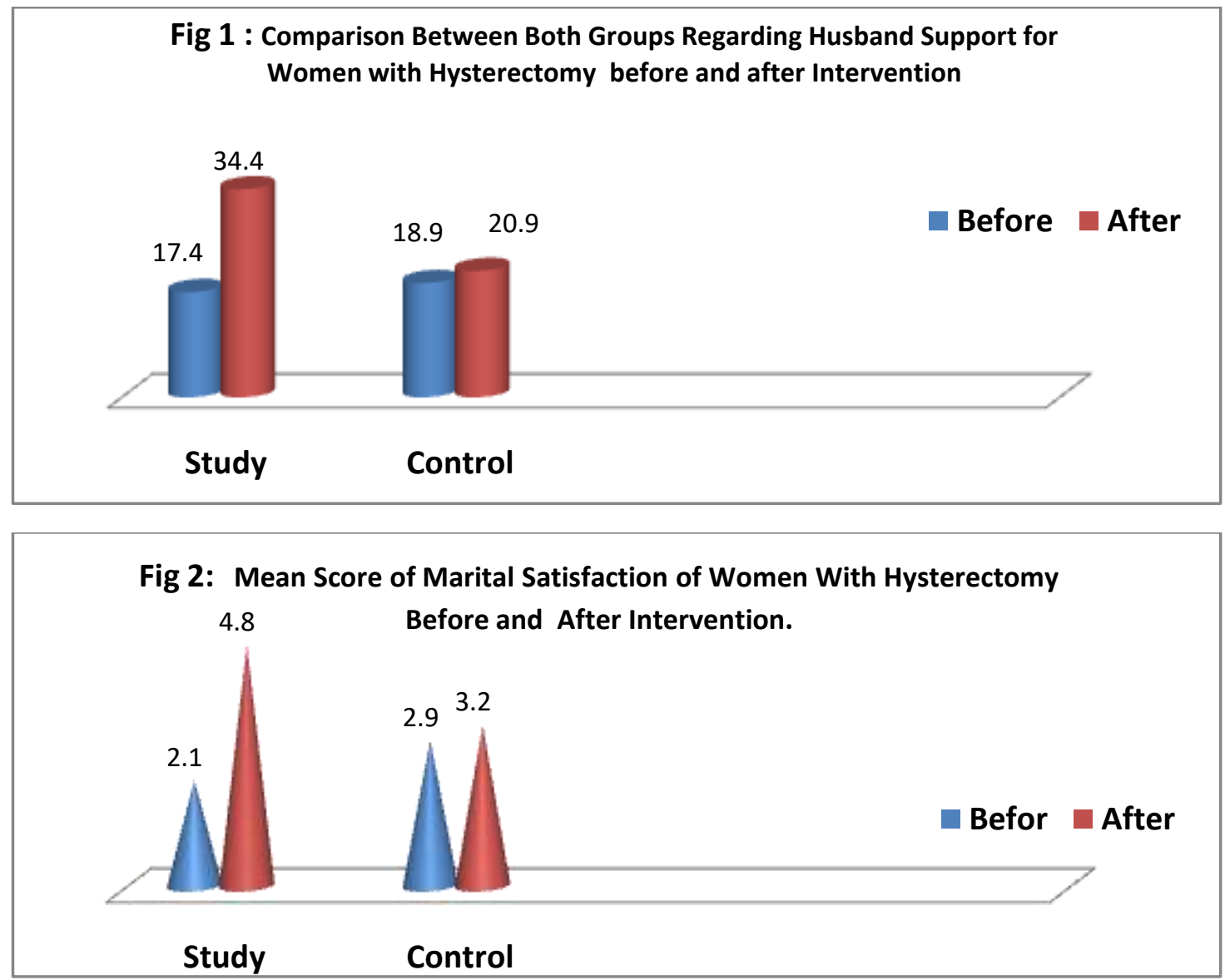

Figure (2): In relation to marital satisfaction, figure (2), represent that the study group was highly satisfied with their sexual desire than the control group. Also within each group, there was marked different at the study group as 
after intervention the satisfaction was markedly higher than before it. Compared to the control group who did not show marked changes unless there was also a source of changes between both groups.

\section{Discussion}

An educational program based on the Roy Adaptation Model (RAM) was applied to women with hysterectomy in the present study, which aimed to address the effect of Roy Adaptation Model on sexual function and spousal support among women with total hysterectomy. Accordingly, an intervention program was developed by using the RAM for eliminating or modifying the focal stimulus as well as for minimizing the effects of contextual and residual stimuli through enhancing women' adaptation capacity. So the current study aimed to address the effect of Roy Adaptation Model on sexual function and spousal support among women with total hysterectomy. Unawareness of their sexual response can prompt sexual problems in women, and beliefs and attitudes are also strong determinants of female sexual function [26] .The study facilities consisted of training sessions and pamphlets, and the women learned skills such as relaxation activities including walking, strengthening exercises for pelvic muscles, use of lubricating gels, and effective communication before having sexual intercourse indicated that the intervention had a positive effect on sexual function after hysterectomy rather than who did not had interventions.

The present findings reflect the positive impact of the program on predisposing factors (knowledge and attitudes) which is consistent with previous results in patients with cancer [27] The positive effect may be due to homogeneity between both groups regarding their socio-demographic \& hysterectomy profile and insignificant dereference in baseline data. These results supported the current study hypothesis which hypothesized that women after hysterectomy and undergo educational intervention based on Roy Adaptation Model will have a positive effect on their sexual function rather than who did not had interventions.

These findings were congruent with two qualitative studies, one from China, the other from Brazil, that men had considerable concerns about changes in postoperative sexuality or sexual abstinence around the time of hysterectomy of their partner $[10,11]$. Unchanged or improved sexual satisfaction for men, with no significant difference after total abdominal hysterectomy or subtotal abdominal hysterectomy, has been reported in a retrospective study from Norway [12]. After hysterectomy, more men noticed during intercourse that the uterus had been removed, but none of these partners experienced this as negative. While some studies report that patients experience greater improvement in their mental health, sexual desire and functioning, and overall satisfaction[ 28,29], others show that patients report various negative outcomes, with detrimental effects on sexual functioning being the main concern[30]. In summary, for the male partner, sexual function after benign hysterectomy appears to be an important issue and some evidence exists that men can also expect unchanged or improved sexual satisfaction, regardless of removal of the cervix.

Many variables that affect marital satisfaction were considered. It is a common opinion that spousal support affects the marital relationship. Many adults perceive marriage as a source of privileged support and emotional intimacy. Moreover, supportive actions are considered important for preventing the start of a set of cognitive and emotional events that would make relationships forced or cause disruptions and conflicts in relationships [31]. According to [32] lack of support is the basis for many problematic marriages, whereas supportive behavior prevents the increase of marital conflicts. Cutrona (1996a) states that perceived spousal support in stressful situations prevents emotional withdrawals, which cause harm to marriages, and that it increases people's belief that they are not alone and that they can easily overcome the situation in question.

During the past decade, there continues to be a lack of research with a focus on partner experience in the context of hysterectomies. [33] Additionally, previous studies have indicated that it is still not certain whether gender difference plays a role in marital satisfaction. Additionally, previous studies have indicated that it is still not certain whether gender difference plays a role in marital satisfaction. While the studies[34,35] conducted by Canel (2007), and Çağ and Yıldırım (2013) indicate that differences in marital satisfaction depend on gender factors, the studies conducted by Çelik and Tümkaya (2012), and Yeşiltepe and Çelik (2014), found no significant differences between marital satisfaction and gender factors. [36,37]

So the current study hypothesized that women with hysterectomy undergo educational intervention based on Roy Adaptation Model will have a high spousal support rather than who did not had interventions. The results of present study supported this hypothesis, which revealed that, spousal support expanded to a moderate level of study group compared to control group as well as marked \& significant differences between the study \& control group after intervention. Spousal support for the purposes of this study was defined as how often a partner feels they can be intimate, confide, and share their worries and fears of woman after hysterectomy and support her.

These positive relations between spousal support and hysterectomy beliefs and intention among Egyptian women are important. Present results showed that women who perceived higher spousal support had more positive beliefs towards a their hysterectomy, including perceived higher benefits, lower barriers, and higher norms. Similar findings regarding the influence of spouse on screening participation was also found in 
another study of colorectal cancers screening conducted in Australia [38].Forbes and colleagues investigated influences on participation in a community-based colorectal cancer screening by colonoscopy. They found that among women, who discussed screening with another individual, the spouse was the most common and such discussion increased the likelihood of screening participation by $23 \%$. [ 38 ]

The present study provided additional quantitative evidence on the influence of spousal support on gynecological cancer screening beliefs among Chinese women Furthermore; current study suggested that women with lower education or health status tend to perceive lower spousal support. This in turn, might negatively influence their screening beliefs or intention. The current finding provides information on important characteristics of women who might be at higher risk of non-adherent to cancer screening recommendations. The finding could help researchers and practitioners identify women with higher vs. lower perceived spousal support for targeted intervention programs.

\section{Conclusion \& Recommendation:}

The findings confirm the effectiveness of an educational program based on Roy Adaptation Model on improving sexual function and Spousal Support among women with hysterectomy. The RAM has positive effects on women's physical and interpersonal sexual adaptation to post-hysterectomy sexual related associated problems. Given its simplicity and easy applicability, the RAM can be used for improving women-related outcomes. Accordingly, the RAM needs to be integrated into many nursing curricula. Considering recommendations, further studies are needed for providing decisive evidence in this area.

\section{References}

[1]. Marta H, Szilvia T, Geza H, Tamas H, Jozsef B, and Janos G. (2015); Quality of Life, Sexual Functions and Urinary Incontinence After Hysterectomy in Hungarian Women. American Journal of Health Research. Vol. 3, No. 6, , pp. 393-398.

[2]. Sheth SS, Paghdiwalla KP, Hajari AR (2011). "Vaginal route: A gynaecological route for much more than hysterectomy". Best Practice \& Research Clinical Obstetrics \& Gynaecology 25 (2): 115-132.

[3]. Marjoribanks, J. Lethaby, A. Farquhar, C. (2006) Surgery versus medical therapy for heavy menstrual bleeding. Cochrane Database of Systematic Reviews. Issue 2

[4]. Selcuk S, Cam C, Asoglu M R b, Kucukbas M a, Arinkan A a, Cikman M S a, Karateke A :Effect of simple and radical hysterectomy on quality of life - analysis of all aspects of pelvic floor dysfunction a European Journal of Obstetrics \& Gynecology and Reproductive Biology 198 (2016) 84-88

[5]. $\quad$ Flory N., Bissonnette F., Binik Y.M.. (2005) Psychosocial effects of hysterectomy: literature review. J Psychosom Res. 59, (3):; 117129.

[6]. Tutuncu B, Yildiz H ( 2012 ): The influence on women's sexual functions of education given according to the PLISSIT model after hysterectomy Procedia - Social and Behavioral Sciences 472000 - 2004

[7]. Hehenkamp W.J., Volkers N.A., Bartholomeus W., de Block S., Birnie E., Reekers J.A., et al. (2007) Sexuality and body image after uterine artery embolisation and hysterectomy in treatment of uterine fibroids: a randomized comparison. Cardiovasc InterventRadiol. 30, (5) ; 866-875

[8]. Sasanpour M., Shahverdyan G.. (2012) The effect of cognitive reconstruction training on sexual problem of couples. $J$ Am Sci. 8, (2): ; 399-403

[9]. Glanz K., Rimer B.K., and Viswanath K.. Health Behavior and Health Education: Theory, Research, and Practice. 2008; JosseyBass: San Francisco

[10]. Chou CC, Lee TY, Sun CC, et al. Husbands' experiences before wives' hysterectomy. J Nurs Res: JNR. 2006;14(2): 113-22.

[11]. Hoga LA, Higashi AB, Sato PM, et al. Psychosexual perspectives of the husbands of women treated with an elective hysterectomy. Health Care Women Int. 2012;33(9):799-813. doi:10.1080/07399332.2011.646370.

[12]. Lonnee-Hoffmann RA, Schei B, Eriksson NH. Sexual experience of partners after hysterectomy, comparing subtotal with total abdominal hysterectomy. Acta ObstetGynecol Scand. 2006;85(11): 1389-94. doi:10.1080/00016340600917316.

[13]. Mossallanejad L, Ashkani H. Motherhood and mental health. 1st ed. Tehran: Ketab-e-Roshan Publication; 2005.

[14]. Younesi SJ, Salajegheh A. Body image in fertile and infertile woman. Med J Reproduction Infertility. 2001; 2(8):14-21.

[15]. Memarian R. Application of nursing concepts and theories. 2nd ed. Tehran: TarbiatModares University Press; 2011. p. 59.

[16]. Roy, C. (1980). "The Roy Adaptation Model". In Riehl, J. P.; Roy, C. Conceptual Models for Nursing Practice. Norwalk: Appleton: Century Crofts.

[17]. AliAkbarzadeArani Z, Taghavi T, Sharifi N, Noghani F, Faghihzade S, Khariarani M. Effect of education on the social adaptation of mothers of trainable retarded children based on Roy adaptation theory. Feiz J. 2012; 16(2):129-34.

[18]. Andrews, H.; Roy, C. (1991). The Adaptation Model. Norwalk: Appleton \& Lange.

[19]. 19 Pour AM, Najafi S, Zadeh JT, Zadeh FM. The effect of intervention based on Roy adaptation model on personal self-concept in primi-gravida women. J SabzevarUniv Med Sci. 2016; 22(6):999-1007.

[20]. Petty B.D. Marriage education: (2007); A Grounded Theory Study of the Positive Influence of the Educational Experience on the Marriage Relationship University of Idaho.

[21]. Julien, J. O., Thom, B., and Kline, N. E., (2010): Identification of barriers to sexual health assessment in oncology nursing practice. Oncology Nursing Forum, (3): 186-190.

[22]. Kotronoulas, G, Papadopoulou, C, and Patiraki, E., (2015): Nurses' knowledge, attitudes, and practices regarding provision of sexual health care in patients with cancer: critical review of the evidence. Support Care Cancer. 17: 479-501.

[23]. Anis T. H., Gheit, S. A., Saied, H. S., and Al kherbash, S. A., (2011): Arabic translation of Female Sexual Function Index and validation in an Egyptian population. J Sex Med., (12): 3370-3378

[24]. Rosen R.C.. Assessment of female sexual dysfunction: review of validated methods. FertilSteril. 77, (Suppl 4): 2002; S89-S93 
[25]. Chang, S.B. 1989. An analytic study on influencing factors for sexual satisfaction in women who have had a hysterectomy. Journal of Korean Academy of Nursing, 19(2):160-172.

[26]. Sasanpour M., Shahverdyan G.. The effect of cognitive reconstruction training on sexual problem of couples. J Am Sci. 8, (2): 2012; 399-403

[27]. Yates P., Edwards H., Nash R., Aranda S., Purdie D., Najman J., et al. A randomized controlled trial of a nurse-administered educational intervention for improving cancer pain management in ambulatory settings. Patient EducCouns. 53, (2): 2004; 227-237

[28]. Yang YL, Chao YM, Chen YC, Yao G. Changes and factors influencing health-related quality of life after hysterectomy in premenopausal women with benign gynecologic conditions. J Formos Med Assoc 2006; 105: 731-742.

[29]. Kuppermann M, Varner RE, Summitt RL et al. Effect of hysterectomy vs medical treatment on health-related quality of life and sexual functioning: The medicine or surgery (Ms) randomized trial. JAMA 2004; 291: 1447-1455.

[30]. Flory N, Bissonnette F, Binik YM. Psychosocial effects of hysterectomy: Literature review. J Psychosom Res 2005; 59: 117-129.

[31]. Lawrence, E., Bunde, M., Barry, R., Brock, R., Sullivan, K., Pasch, L.Adams, E. (2008). Partner support and marital satisfaction: Support amount, adequacy, provision, and solicitation. Personal Relationships, 15, 445-463.

[32]. Rugel, R. P. (1997). Husband-focused marital therapy: An approaches to dealing with marital distress. Springfield, III: Charles C. Thomas, Publisher Ltd.

[33]. Cutrona, C. E. (1996a). Social support in couples: Marriage as a resource in times of stress. Thousand Oaks, CA: Sage.

[34]. Canel, A. N. (2007). Ailede problem çözme, evlilikdoyumuveörnekbirgrupçalışmasınınsınanması (Doctoral dissertation, Marmara University, Ístanbul, Turkey). Retrieved from https://tez.yok.gov.tr/UlusalTezMerkezil

[35]. Çă̆, P., \&Yıldırım, İ. (2013). Evlilikdoyumunuyordayanilișkiselvekișiseldeğișkenler [Relational and personal variables of the predictors of marital satisfaction]. TürkPsikolojikDanışmaveRehberlikDergisi, 4(39), 13-23.

[36]. Çelik, M., \&Tümkaya, S. (2012)Öğretimelemanlarınınevliliku yumuveyaşamdoyumlarınınişdeğişkenleriileilişkisi. Ahi EvranÜniversitesiKırșehirEğitimFakültesiDergisi, 13(1), 223-238

[37]. Yeşiltepe, S. S., \&Çelik, M. (2014). Evaluation of marital adjustment of teachers in terms of psychological well-being and some variables.Elementary Education Online, 13(3), 992-1013

[38]. Forbes, G. M., Fritschi, L., Mendelson, R. M., Foster, N. M., \& Edwards, J. T. (2004). Influences on participation in a communitybased colorectal neoplasia screening program by virtual colonoscopy in Australia. Australia New Zealand Journal of Public Health, 28(3), 283-287. 